\title{
Vascular Cambium: The Source of Wood Formation
}

\author{
Dian Wang ${ }^{1}$, Yan Chen ${ }^{2}$, Wei $\mathrm{Li}^{3}$, Quanzi $\mathrm{Li}^{4}$, Mengzhu $\mathrm{Lu}^{5}$, Gongke Zhou ${ }^{6 *}$ and \\ Guohua Chai ${ }^{6 *}$ \\ ${ }^{1}$ College of Agronomy, Qingdao Agricultural University, Qingdao, China, ${ }^{2}$ College of Landscape Architecture and Forestry, \\ Qingdao Agricultural University, Qingdao, China, ${ }^{3}$ State Key Laboratory of Tree Genetics and Breeding, Northeast Forestry \\ University, Harbin, China, ${ }^{4}$ State Key Laboratory of Tree Genetics and Breeding, Chinese Academy of Forestry, Beijing, \\ China, ${ }^{5}$ State Key Laboratory of Subtropical Silviculture, School of Forestry and Biotechnology, Zhejiang A\&F University, \\ Hangzhou, China, ${ }^{6}$ College of Resources and Environment, Qingdao Agricultural University, Qingdao, China
}

\section{OPEN ACCESS}

Edited by:

Raju Datla,

Global Institute for Food Security (GIFS), Canada

Reviewed by:

Melis Kucukoglu,

University of Helsinki, Finland

Célia M. Miguel,

University of Lisbon, Portugal

${ }^{*}$ Correspondence:

Guohua Chai

chaigh@qau.edu.cn

Gongke Zhou

zhougk@qau.edu.cn

Specialty section:

This article was submitted to Plant Development and EvoDevo, a section of the journal

Frontiers in Plant Science

Received: 27 April 2021

Accepted: 27 July 2021

Published: 18 August 2021

Citation:

Wang D, Chen Y, Li W, Li Q, Lu M, Zhou G and Chai G (2021) Vascular

Cambium: The Source of Wood Formation.

Front. Plant Sci. 12:700928. doi: 10.3389/fp/s.2021.700928
Wood is the most abundant biomass produced by land plants and is mainly used for timber, pulping, and paper making. Wood (secondary xylem) is derived from vascular cambium, and its formation encompasses a series of developmental processes. Extensive studies in Arabidopsis and trees demonstrate that the initiation of vascular stem cells and the proliferation and differentiation of the cambial derivative cells require a coordination of multiple signals, including hormones and peptides. In this mini review, we described the recent discoveries on the regulation of the three developmental processes by several signals, such as auxin, cytokinins, brassinosteroids, gibberellins, ethylene, TDIF peptide, and their cross talk in Arabidopsis and Populus. There exists a similar but more complex regulatory network orchestrating vascular cambium development in Populus than that in Arabidopsis. We end up with a look at the future research prospects of vascular cambium in perennial woody plants, including interfascicular cambium development and vascular stem cell regulation.

Keywords: wood, vascular cambium, hormones and peptides, cross talk regulation, Arabidopsis and Populus

\section{INTRODUCTION}

Vascular plants, particularly tree species, undergo two distinct phases of growth and development. During primary growth, shoot apical meristems (SAMs) and root apical meristems (RAMs) are responsible for the aboveground and underground organ growth, respectively. At the peripheral region of SAM, procambium cells produce primary vascular bundles (Figure 1; also see Nieminen et al., 2015). After the primary vascular system is established, fascicular cambium located at the center of primary vascular bundles undergoes extension into the interfascicular region, forming a ring of vascular cambium (Figure 1; Nieminen et al., 2015). Vascular cambium is a cylindrical secondary meristem whose activity gives rise to the secondary growth. Like SAM and RAM, vascular cambium contains bifacial cambium stem cells in Arabidopsis (Shi et al., 2019; Smetana et al., 2019). However, stem cell activities of the three types of meristems are preferentially regulated by different members of the WUSCHEL-RELATED HOMEOBOX (WOX) and CLAVATA3/EMBRYO SURROUNDING REGION-RELATED (CLE) gene families: SAM is associated with WUSCHEL (WUS) and CLAVATA3 (CLV3; Mayer et al., 1998; Schoof et al., 2000), RAM with WOX5 and 


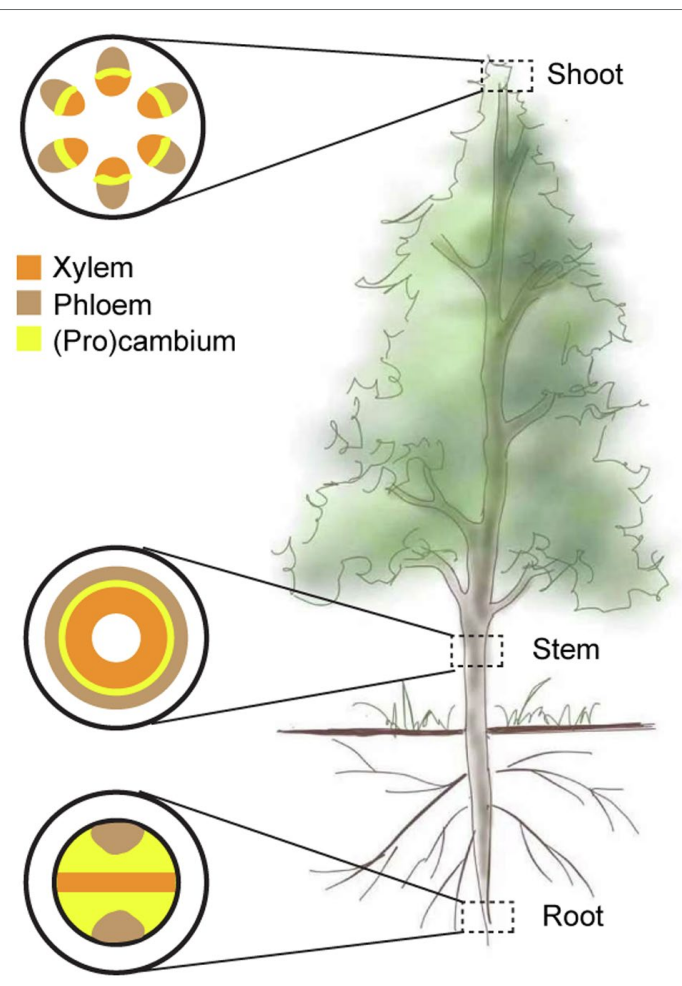

FIGURE 1 | A schematic view of vascular tissue organization in shoot, stem, and root of vascular plants. Xylem and phloem tissues are initiated from procambium in vascular plants. Shoot apical meristems and root apical meristems are two primary meristems, and vascular cambium is a cylindrical secondary meristem in stems. The xylem is represented in orange, the phloem in brown, and the cambium in yellow.

CLE40 (Sarkar et al., 2007; Berckmans et al., 2020), and vascular cambium with WOX4 and CLE41/44 (Hirakawa et al., 2010; Ji et al., 2010).

Secondary xylem (wood) and phloem are the inner and outer derivative products of the vascular cambium. Xylem is mainly comprised with dead cells with thickened cell walls rich in cellulose, hemicelluloses, and lignin and responsible for providing mechanical support and conducting water and minerals for the plant. Phloem transports photoassimilates and signaling molecules, including phytohormones and peptides, from the source organs to the sink organs. Fusiform initials and ray initials are morphologically distinct meristematic cells in vascular cambium of woody stems (Mauseth, 2016). The fusiform initials ( $>90 \%$ of the vascular cambium) are oriented longitudinally relative to the stem and undergo periclinal divisions that produce phloem and xylem mother cells (Mizrachi and Myburg, 2016; Fischer et al., 2019). The ray initials are isodiametric and produce the radially orientated ray cells that serve radial transport and storage.

The activity of the vascular cambium is regulated by endogenous developmental programs and environmental cues. In recent years, considerable progress in the molecular mechanism of the development of vascular cambium has been achieved in the model plants Arabidopsis and Populus. It has been shown that the establishment and maintenance of vascular cambium involve the coordination of multiple regulators, including hormones, peptides, and transcription factors (Figure 2; also see the reviews by Miyashima et al., 2013; Mizrachi and Myburg, 2016; Chiang and Greb, 2019). However, our knowledge about the development and regulation of vascular cambium, compared to SAM and RAM, is limited. This mini review focuses on recent progresses in the regulatory networks responsible for the vascular cambium identity and activity in poplar.

\section{ESTABLISHMENT OF THE VASCULAR CAMBIUM}

Because vascular procambial cells are imbedded under layers of other tissues in stems, our current understanding of procambium initiation and regulation is derived from studies in Arabidopsis embryos, RAMs, and leaf venation systems. Functional characterization of a serial of Arabidopsis mutants shows that vascular cambium initiation requires the cross talk regulation of multiple hormones (Figure 2A). Auxin plays a central role in regulating the initiation and maintenance of procambial stem cells (Ibañes et al., 2009; Weijers and Wagner, 2016). In pre-procambial strands, MONOPTEROS (MP)/AUXIN RESPONSE FACTOR 5 (ARF5) is activated in response to auxin and positively regulates the number of vascular initial cells through induction of the expression of the auxin efflux carrier gene PIN-FORMED1 (PIN1; Wenzel et al., 2007). Periodic auxin maxima controlled by polar transport but not overall auxin levels is required to determine the radial pattern of vascular bundles in postembryonic growth (Ibañes et al., 2009). MP/ARF5 positively regulates TARGET OF MONOPTEROS 5 (TMO5), which forms a dimer complex with LONESOME HIGHWAY (LHW) to control the procambium cell divisions in roots (De Rybel et al., 2014; Ohashi-Ito et al., 2014). MP/ARF5 activates ATHB8-targeted PIN1 in response to auxin, forming a self-reinforcing mechanism of auxin flow during the formation of vein procambium (Donner et al., 2009). ATHB8, a HD-ZIP III transcription factor, is shown to restrict preprocambial cell specification to a narrow zone and stabilize preprocambial cell fate (Baima et al., 2001; Donner et al., 2009). REVOLUTA is another member of the Arabidopsis HD-ZIP III gene family, and its Populus ortholog, PopREVOLUTA, influences vascular cambium initiation in Populus stems (Robischon et al., 2011).

Cytokinin $(\mathrm{CK})$ is another major hormone that regulates procambium identity and activity in Arabidopsis (Figure 2A). Mutation of three CK receptor genes CYTOKININ RESPONSE 1 (CRE1), ARABIDOPSIS HISTIDINE KINASE 2 (AHK2), and $A H K 3$ results in a severely reduced numbers of periclinal divisions in the procambium cells of the primary roots (Inoue et al., 2001). Accordingly, transgenic Arabidopsis plants overexpressing CYTOKININ OXIDASES/DEHYDROGENASES 2 (CKX2), a CK degrading enzyme gene, under the control of CRE1 promoter show the crelahk2ahk3 phenotype (Mähönen et al., 2006). Moreover, the establishment of 

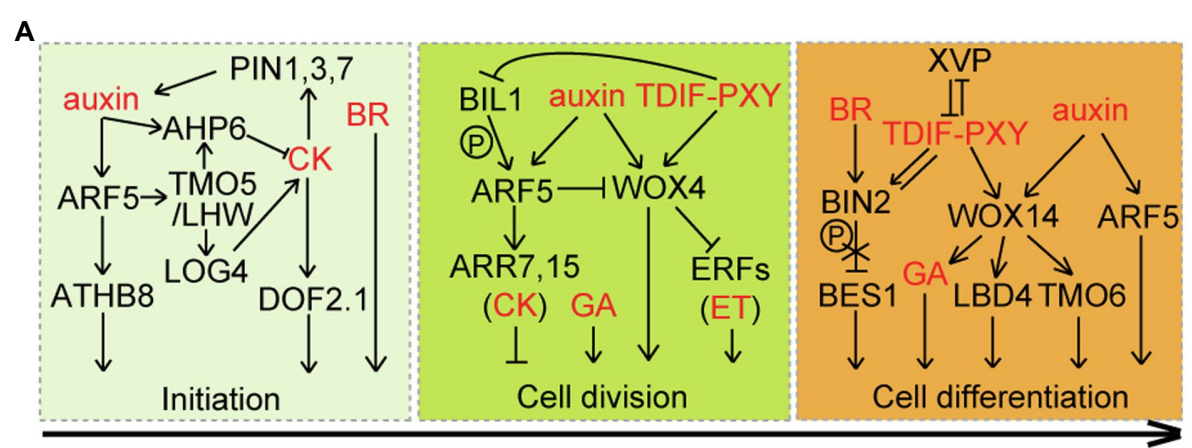

Vascular cambium development

B

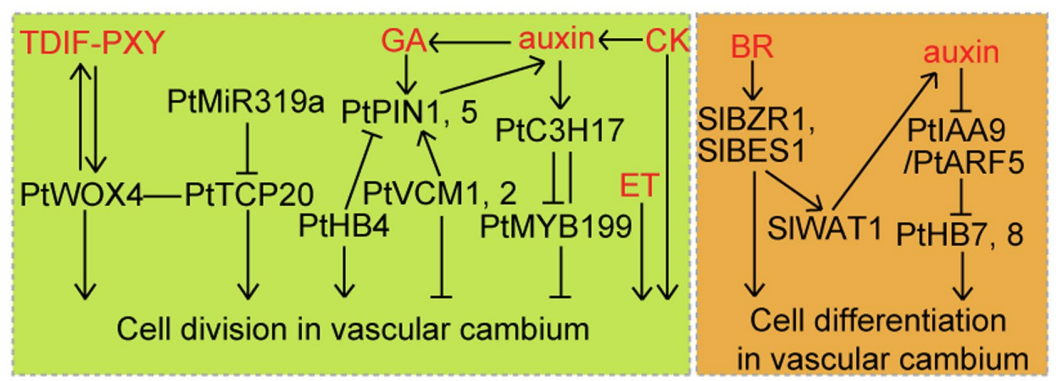

FIGURE 2 | Coordination of multilayered signaling pathways on vascular cambium. (A) In Arabidopsis, vascular cambium initiation and the proliferation and differentiation of cambia derivative cells require a coordination of multiple signals, including auxin, cytokinin (CK), brassinosteroid (BR), gibberellin (GA), ethylene (ET), and TDIF-PXY. TDIF peptides are synthesized in the phloem and move to the cambium at which they bind to the PXY receptor. (B) Cross talk regulation of cell division and differentiation by multiple signals in the vascular cambium of Populus (Pt) and tomato (SI) stems. There is a similar but more complex regulatory network orchestrating vascular cambium development in Populus than that in Arabidopsis.

procambium cell identity requires a mutually inhibitory interaction between $\mathrm{CK}$ and auxin signaling (Figure 2A). Reduced CK signaling changes the subcellular polarity of PIN1, PIN3, and PIN7, while auxin is able to activate the expression of ARABIDOPSIS HISTIDINE PHOSPHOTRANSFER 6 (AHP6), an inhibitor of CK signaling (Mähönen et al., 2006; Bishopp et al., 2011). Auxin-induced TMO5/LHW dimer directly activates LONELY GUY 4 (LOG4) that encodes for a rate-limiting enzyme in CK biosynthesis (De Rybel et al., 2014). CK-dependent procambium cell divisions are controlled by the DOF transcription factor DOF2.1 downstream of TMO5/LHW (Smet et al., 2019).

Brassinosteroids (BRs) serve as a key promoting signal for procambial division during primary growth (Figure 2A). In the stem of Arabidopsis, the number of vascular bundles (VB) is obviously increased in gain-of-function BR-signaling mutants, such as brassinosteroid insensitive 2 (bin2) and brassinazoleresistant 1-1D (bzr1-1D), while loss-of-function BR-signaling mutant brassinosteroid insensitive 1-116 (bri1-116) and BR synthesis mutant constitutive photomorphogenesis and dwarfism (cpd) have fewer VBs than wild-type plants (Ibañes et al., 2009).

\section{REGULATION OF VASCULAR CAMBIUM ACTIVITY}

Trees display prominent secondary growth in the stem and root, with similar vascular cell types to Arabidopsis
(Mizrachi and Myburg, 2016). Studies in Arabidopsis stems and roots indicate an important regulatory function for hormones (auxin, CK, and ethylene) and TRACHEARY ELEMENT DIFFERENTIATION INHIBITORY FACTOR (TDIF) peptide in the proliferation of vascular cambium (Ortega-Martinez et al., 2007; Matsumoto-Kitano et al., 2008; Suer et al., 2011; Fischer et al., 2019; Smetana et al., 2019). WOX4 is considered to be a central regulator of vascular cambium division (Figure 2A), because it activates a cambium-specific transcriptional network and integrates auxin, ethylene, and TDIF-PXY (PHLOEM INTERCALATED WITH XYLEM) signaling for cambium division (Hirakawa et al., 2010; Ji et al., 2010; Suer et al., 2011; Etchells et al., 2012; Brackmann et al., 2018; Zhang et al., 2019). WOX4 is required for auxin-dependent stimulation of cambium activity (Suer et al., 2011). Auxininduced MP/ARF5 directly attenuates the activity of the stem cell-promoting WOX4 gene, and cell-autonomously restricts the number of stem cells in stems (Brackmann et al., 2018). The TDIF peptides encoded by CLE41 and CLE44 are synthesized in the phloem and travel to the cambium where they bind and activate PXY, stimulating WOX4 transcription and promoting cambium proliferation in stems (Hirakawa et al., 2010). Ethylene and TDIF signaling converge at WOX4 to regulate cambium activity (Etchells et al., 2012; Yang et al., 2020b). BIN2-LIKE 1 (BIL1), a glycogen synthase kinase 3 , functions as a mediator that links auxin-CK signaling with TDIF-PXY signaling for the maintenance of cambial activity (Han et al., 2018). 
Phosphorylation of MP/ARF5 by BIL1 enhances its negative effect on the activity of vascular cambial, which upregulates ARABIDOPSIS RESPONSE REGULATOR 7 (ARR7) and ARR15, two negative regulators of CK signaling. BIL1 activity is inhibited by PXY, attenuating the effect of MP/ARF5 on ARR7 and $A R R 15$ expressions and increasing vascular cambial activities.

Regulation of vascular cambium activity by auxin, CK, ethylene, and TDIF-PXY signaling is relatively conserved between trees and Arabidopsis (Figure 2). Auxin shows the highest level at the cambium zone, and its level declines near the mature xylem cells during wood formation in trees (Nilsson et al., 2008; Immanen et al., 2016). Overexpression of the stabilized form of INDOLE ACETIC ACID 3 (IAA3) that perturbs auxin signaling in hybrid aspen represses periclinal division of cambial cells but enlarges cell file harboring anticlinal cell division (Nilsson et al., 2008). Auxin-responsive PaC3H17PaMYB199 module promotes cambium division by a dual regulatory mechanism in Populus stems (Tang et al., 2020). Auxin promotes direct repression of PaMYB199 expression by $\mathrm{PaC} 3 \mathrm{H} 17$ and also enhances the PaC3H17-PaMYB199 interaction, attenuating PaMYB199 inhibition of cambial cell division. Consistent with this, dominant repressors of $\mathrm{PaC} 3 \mathrm{H} 17$ or overexpression of PaMYB199 result in a reduction in the number of cambial cell layers, while transgenic poplars overexpressing $\mathrm{PaC} 3 \mathrm{H} 17$ or repressing PaMYB199 have the opposite phenotype. In addition, the regulation of vascular cambium activity is associated with feedback mediation of auxin homeostasis in trees. Downregulation of the Populus HD-ZIP III gene PtrHB4 enhances PtrPIN1 expression and causes drastic defects in interfascicular cambium, indicating that PtrHB4 induces interfascicular cambium formation during the development of the secondary vascular system (Zhu et al., 2018). VASCULAR CAMBIUM-RELATED MADS 1 (VCM1) and VCM2 inhibit vascular cambium proliferation activity and secondary growth through direct upregulation of PtrPIN5 expression in Populus stems (Zheng et al., 2021). These findings indicate more fine regulation of cambial activity by auxin signaling in trees than in Arabidopsis.

$\mathrm{CK}$ is another important regulator of cambial activity during wood formation (Figure 2B). Inhibition of cambial CK signaling by overexpression of Arabidopsis AtCKX2 under the promoter of a birch CRE1 gene leads to a reduced number of cambial cells in poplar stems, while increased vascular division is observed in transgenic poplars expressing the Arabidopsis CK biosynthetic gene ISOPENTENYL TRANSFERASE 7 (IPT7) under the control of the cambium-specific PttLMX5 promoter (Nieminen et al., 2008; Immanen et al., 2016). Elevated CK levels cause an increase of auxin level at the cambium zone, highlighting the interconnected nature of auxin and CK gradients (Immanen et al., 2016). A recent study uncovers the mechanism of CK signaling associated with its spatial enrichment to regulate vascular development in Populus (Fu et al., 2021). The local CK signaling in the developing secondary phloem regulates the activity of vascular cambium in a non-cell-autonomous manner.

In addition to auxin and CK, gibberellin (GA), ethylene, and TDIF-PXY signaling promote cambial cell division and radial growth in trees (Figure 2B). Transgenic poplar lines overexpressing
GA 20-OXIDASE, encoding a GA biosynthesis enzyme, promote over-production of GA and cambium proliferation (Eriksson et al., 2000). Ethylene-overproducing and ethylene-insensitive poplars show increased and reduced cambium division, respectively (Love et al., 2009). Overexpression of PttCLE41, a TDIF-like peptide, together with its receptor PttPXYa affects the rate of cambial cell division and woody tissue organization in both hybrid aspen and poplar (Etchells et al., 2015; Kucukoglu et al., 2017). PttWOX4 stimulates the cambium proliferation downstream of TDIF-PXY signaling, as is similar to the manner of the Arabidopsis TDIF-PXY-WOX module. One difference is that in Populus, PttWOX4a/b expression is not responsive to auxin treatments, but upstream genes, such as PttPXYa and PttCLE41a/d, are responsive (Kucukoglu et al., 2017). The cross talk of hormones in regulation of cambium activity was also found in trees. For instance, GA coordinates with auxin for inducing cambium division through upregulating $83 \%$ of auxin-responsive genes, including PttPIN1, while auxin treatment upregulates GA biosynthesis genes and downregulates GA degradation genes in wood-forming tissues (Björklund et al., 2007).

\section{REGULATION OF CAMBIUM DERIVATIVE CELLS DIFFERENTIATION}

The regulatory roles of auxin, BR, and GA in cell differentiation in the vascular cambium are studied in Arabidopsis or/and trees (Figure 2). Since 20 years ago, the IAA12/BODENLOS (BDL)-ARF5/MP module in auxin signaling has been identified to control provascular specification and patterning during embryo-genesis in Arabidopsis (Hardtke and Berleth, 1998). Recently, the PtoIAA9-PtoARF5 module from Populus has been validated to mediate auxin-triggered cell differentiation of early developing xylem (Xu et al., 2019). With auxin treatment, PtoIAA9 protein is degraded, inducing PtoARF5-activated gene expression, and the activated PtoIAA9 switches-off auxin signaling in a self-controlled manner during wood formation. BRs play a regulatory role in differentiation of vascular tissues, in addition to inducing cambium initiation during primary growth. Mutation of both BRI-LIKE 1 (BRL1) and BRL3, two Arabidopsis vascularspecific BR receptors, causes expanded phloem development at the expense of xylem in stems (Cano-Delgado et al., 2004). bri1-ethylmethylsulfone-suppressor 1-D (bes1-D), a gain-offunction BR-signaling mutants, exhibits an increase of xylem differentiation (Kondo et al., 2014). Similarly, inhibition of BR synthesis results in decreased secondary vascular differentiation and cell wall biosynthesis, while elevated BR levels cause increases in secondary growth in Populus (Du et al., 2020). A recent study indicates that BR signaling is tightly connected with local intracellular auxin homeostasis during cell differentiation in the vascular cambium of tomato stems (Lee et al., 2021). BZR1/BES1-activated WALLS ARE THIN1 (WAT1), an auxin efflux carrier, facilitates cell differentiation in the vascular cambium by enhancing local auxin signaling. In addition, GA is shown to induce vascular cell differentiation and lignification downstream of WOX14 gene in the stem of Arabidopsis (Mauriat and Moritz, 2009; Denis et al., 2017). 
TDIF-PXY signaling is a mediator that induces cell differentiation in the vascular cambium in Arabidopsis (Figure 2A). Transgenic plants overexpressing CLE41 or CLE44 display abnormal vascular patterning with a xylem intermixed with phloem phenotype during both primary and secondary growths (Fisher and Turner, 2007; Etchells and Turner, 2010). TDIF signaling regulation of xylem differentiation is fine-tuned by the NAC transcription factor XYLEM DIFFERENTIATION AND ALTERED VASCULAR PATTERNING (XVP; Yang et al., 2020a). XVP negatively regulates the TDIF-PXY module, and it also forms a complex with TDIF co-receptors PXY-BAK1 (BRI1-associated receptor kinase 1). XVP expression is suppressed by TDIF by a feedback mechanism. Overexpression of PttCLE41 or PttPXY (the orthologs to Arabidopsis CLE41 and $P X Y$, respectively) in hybrid aspen or poplar causes defects in the patterning of the vascular tissues and shows inhibited plant growth (Etchells et al., 2015; Kucukoglu et al., 2017), suggesting a similar regulation of xylem differentiation by the TDIF-PXY module in trees. The cross talk between TDIF-PXY signaling module and BR or auxin occurs in controlling vascular cell differentiation in Arabidopsis (Figure 2A). PXY physically interacts with BIN2 at the plasma membrane, and the treatments by TDIF peptide enhance the activity of BIN2 in a PXY-dependent manner (Kondo et al., 2014). Transcriptional regulatory network mediated by PXY comprises 690 transcription factor-promoter interactions, of which a feed-forward loop containing WOX14, TMO6 and their downstream gene LATERAL ORGAN BOUNDARIES DOMAIN4 (LBD4) determines the arrangement of vascular tissue (Smit et al., 2020).

The HD-ZIP III and NAC transcription factors are important regulators of vasculature organization. In Arabidopsis vascular tissues, mutation of one or several members of HD-ZIP III family results in an amphicribal vascular bundle pattern (phloem surrounding xylem), whereas gain-of-function mutants display amphivasal bundles (McConnell et al., 2001; Emery et al., 2003; Ramachandran et al., 2017). PtrHB5 and PtrHB7 are the orthologs of Arabidopsis POPCORONA and AtHB8 in Populus, respectively. Both genes correspondingly induce cambium activity and xylem differentiation in stems during secondary growth (Du et al., 2011; Zhu et al., 2013). Interestingly, PtrHB7 was identified as a direct target of the PtrIAA9-PtrARF5 module during xylem cell differentiation (Xu et al., 2019). This places PtrHB7 in the regulatory network of auxin-induced xylem differentiation in woody stems. The Arabidopsis NAC genes VASCULAR-RELATED NAC DOMAINs $(V N D s)$ act as master regulators of xylem differentiation capable of switching on the developmental program (Kubo et al., 2005; Zhou et al., 2014), while other members of this family, NAC SECONDARY WALL THICKENING PROMOTING FACTOR 1, 3 (NST1, 3), can promote fiber differentiation in stems (Zhong et al., 2006; Mitsuda et al., 2007). Four Populus orthologs of NST1/3 redundantly control SCW formation in xylem fibers, phloem fibers, and xylem ray parenchyma cells (Takata et al., 2019), indicating a conserved role of these NACs in wood formation. Some NAC genes impede xylem differentiation and secondary wall deposition involving PagKNAT2/6b and PtoTCP20 in Populus (Hou et al., 2020; Zhao et al., 2020). PagKNAT2/6b directly activates PagXND1a expression but represses PagNST3s and PagVND6 expression in wood-forming tissues (Zhao et al., 2020).
PtoTCP20 interacts with PtoWOX4a to control vascular cambium proliferation and also activates PtoWND6 expression to promote secondary xylem differentiation (Hou et al., 2020).

\section{FUTURE OUTLOOK}

Wood formation of tree species involves a complex regulatory network underlying cambial initiation, tissue patterning, and cell differentiation. Understanding the vascular cambium development is a basis for genetic modification of wood biomass and properties in trees. Extensive studies in the model tree Populus indicate the cross talk regulation of vascular cambium development by multiple signals, including auxin, $\mathrm{CK}, \mathrm{BR}$, and TDIF-PXY, similar to regulatory programs of Arabidopsis vascular development (Figure 2). However, based on genome sequences, it is predicted that 1.4 1.6 Populus homologs correspond to each Arabidopsis gene (Tuskan et al., 2006). These Populus duplicated genes may undergo divergent fates, such as nonfunctionalization (loss of original functions), neofunctionalization (acquisition of novel functions), or subfunctionalization (partition of original functions). This may explain the emerging more complex mechanisms underlying vascular cambium maintenance and differentiation in trees than in Arabidopsis.

In recent years, the studies on the vascular cambium formation and regulation in trees have been greatly facilitated by new technologies, such as the genome-editing, integrated-omics, and more advanced microscopy. Therefore, the following key questions are anticipated to be addressed in the near future.

1. How do the interfascicular cambial cells function in woody stems?

With the onset of the secondary growth, fascicular cambia are interconnected with interfascicular cambia located between the vascular bundles, forming a complete vascular cambium in woody stems (Figure 1). The interfascicular cambia are known to originate from the parenchymatic cells in the interfascicular region. Currently, our understanding regarding how the parenchymatic cells differentiate and develop into new procambium strands in the interfascicular region is limited, compared with extensive studies on fascicular cambia. To our knowledge, the HD-ZIP III gene PtrHB4 is the only gene that is shown to induce interfascicular cambium division in Populus stems (Zhu et al., 2018). Analysis of time-spatial features of parenchymatic cells action and mining the related genes in trees are essential in the future. The application of single-cell RNA sequencing, computational modeling, or biosensor may be helpful for addressing this question.

2. How is the vascular cambium activity maintained in trees?

Vascular cambium of trees is able to ensure both increased stem girth and annual renewal of vascular tissues over its lifespan. Even in 667-year-old Ginkgo biloba trees, the vascular cambium still maintains activity (Wang et al., 2020). A key question for wood biology is how vascular cambium activity maintained? In Populus, multiple signals mediate the coordinated regulation of vascular cambium activity, as is more complex than that in Arabidopsis (Figure 2). It is therefore critical to investigate what signals and how these signals drive the activity of cambial stem cells under certain circumstances? Identification of reliable cell-specific makers thus to analyze gene expression 
in each layer of cambial cells is essential for understanding the gene regulation of vascular stem cells in trees.

\section{AUTHOR CONTRIBUTIONS}

DW and GC drafted the manuscript. GZ, YC, WL, QL, and $\mathrm{ML}$ edited the manuscript. All authors approved the final version.

\section{REFERENCES}

Baima, S., Possenti, M., Matteucci, A., Wisman, E., Altamura, M. M., Ruberti, I., et al. (2001). The Arabidopsis ATHB-8 HD-zip protein acts as a differentiationpromoting transcription factor of the vascular meristems. Plant Physiol. 126, 643-655. doi: 10.1104/pp.126.2.643

Berckmans, B., Kirschner, G., Gerlitz, N., Stadler, R., and Simon, R. (2020). CLE40 signaling regulates root stem cell fate. Plant Physiol. 182, 1776-1792. doi: $10.1104 / p p .19 .00914$

Bishopp, A., Help, H., El-Showk, S., Weijers, D., Scheres, B., Friml, J., et al. (2011). A mutually inhibitory interaction between auxin and cytokinin specifies vascular pattern in roots. Curr. Biol. 21, 917-926. doi: 10.1016/j. cub.2011.04.017

Björklund, S., Antti, H., Uddestrand, I., Moritz, T., and Sundberg, B. (2007). Cross-talk between gibberellin and auxin in development of Populus wood: gibberellin stimulates polar auxin transport and has a common transcriptome with auxin. Plant J. 52, 499-511. doi: 10.1111/j.1365-313X.2007.03250.x

Brackmann, K., Qi, J., Gebert, M., Jouannet, V., Schlamp, T., Grunwald, K., et al. (2018). Spatial specificity of auxin responses coordinates wood formation. Nat. Commun. 9:875. doi: 10.1038/s41467-018-03256-2

Cano-Delgado, A., Yin, Y., Yu, C., Vafeados, D., Mora-Garcia, S., Cheng, J. C., et al. (2004). BRL1 and BRL3 are novel brassinosteroid receptors that function in vascular differentiation in Arabidopsis. Development 131, 5341-5351. doi: $10.1242 /$ dev.01403

Chiang, M. H., and Greb, T. (2019). How to organize bidirectional tissue production? Curr. Opin. Plant Biol. 51, 15-21. doi: 10.1016/j.pbi.2019.03.003

De Rybel, B., Adibi, M., Breda, A. S., Wendrich, J. R., Smit, M. E., Novák, O., et al. (2014). Plant development. Integration of growth and patterning during vascular tissue formation in Arabidopsis. Science 345:1255215. doi: 10.1126/ science. 1255215

Denis, E., Kbiri, N., Mary, V., Claisse, G., Silva, N. C., Kreis, M., et al. (2017). WOX14 promotes bioactive gibbrellin synthesis and vascular cell differentiation in Arabidopsis. Plant J. 90, 560-572. doi: 10.1111/tpj.13513

Donner, T. J., Sherr, I., and Scarpella, E. (2009). Regulation of preprocambial cell state acquisition by auxin signaling in Arabidopsis leaves. Development 136, 3235-3246. doi: 10.1242/dev.037028

Du, J., Gerttula, S., Li, Z., Zhao, S., Liu, Y., Liu, Y., et al. (2020). Brassinosteroid regulation of wood formation in poplar. New Phytol. 225, 1516-1530. doi: 10.1111/nph.15936

Du, J., Miura, E., Robischon, M., Martinez, C., and Groover, A. (2011). The Populus Class III HD ZIP transcription factor POPCORONA affects cell differentiation during secondary growth of woody stems. PLoS One 6:e17458. doi: 10.1371/journal.pone.0017458

Emery, J. F., Floyd, S. K., Alvarez, J., Eshed, Y., Hawker, N. P., Izhaki, A., et al. (2003). Radial patterning of Arabidopsis shoots by class III HD-ZIP and KANADI genes. Curr. Biol. 13, 1768-1774. doi: 10.1016/j.cub.2003.09.035

Eriksson, M. E., Israelsson, M., Olsson, O., and Moritz, T. (2000). Increased gibberellin biosynthesis in transgenic trees promotes growth, biomass production and xylem fiber length. Nat. Biotechnol. 18, 784-788. doi: $10.1038 / 77355$

Etchells, J. P., Mishra, L. S., Kumar, M., Campbell, L., and Turner, S. R. (2015). Wood formation in trees is increased by manipulating PXY-regulated cell division. Curr. Biol. 25, 1050-1055. doi: 10.1016/j.cub.2015.02.023

Etchells, J. P., Provost, C. M., and Turner, S. R. (2012). Plant vascular cell division is maintained by an interaction between PXY and ethylene signalling. PLoS Genet. 8:e1002997. doi: 10.1371/journal.pgen.1002997

\section{FUNDING}

Financial support for this work was obtained from the National Key Scientific Research Project of China (2016YFD0600104), the National Natural Science Foundation of China (31972955, 31770315, 31972860, and 31900227), the Taishan Scholar Program of Shandong (tsqn202103092), and First Class Grassland Science Discipline Program of Shandong Province.

Etchells, J. P., and Turner, S. R. (2010). The PXY-CLE41 receptor ligand pair defines a multifunctional pathway that controls the rate and orientation of vascular cell division. Development 137, 767-774. doi: $10.1242 /$ dev.044941

Fischer, U., Kucukoglu, M., Helariutta, Y., and Bhalerao, R. P. (2019). The dynamics of cambial stem cell activity. Annu. Rev. Plant Biol. 70, 293-319. doi: 10.1146/annurev-arplant-050718-100402

Fisher, K., and Turner, S. (2007). PXY, a receptor-like kinase essential for maintaining polarity during plant vascular-tissue development. Curr. Biol. 17, 1061-1066. doi: 10.1016/j.cub.2007.05.049

$\mathrm{Fu}, \mathrm{X}$., Su, H., Liu, S., Du, X., Xu, C., and Luo, K. (2021). Cytokinin signaling localized in phloem noncell-autonomously regulates cambial activity during secondary growth of Populus stems. New Phytol. 230, 1476-1488. doi: 10.1111/ nph.17255

Han, S., Cho, H., Noh, J., Qi, J., Jung, H. J., Nam, H., et al. (2018). BIL1mediated MP phosphorylation integrates PXY and cytokinin signalling in secondary growth. Nat. Plants 4, 605-614. doi: 10.1038/ s41477-018-0180-3

Hardtke, C. S., and Berleth, T. (1998). The Arabidopsis gene MONOPTEROS encodes a transcription factor mediating embryo axis formation and vascular development. EMBO J. 17, 1405-1411. doi: 10.1093/ emboj/17.5.1405

Hirakawa, Y., Kondo, Y., and Fukuda, H. (2010). TDIF peptide signaling regulates vascular stem cell proliferation via the WOX4 homeobox gene in Arabidopsis. Plant Cell 22, 2618-2629. doi: 10.1105/tpc.110.076083

Hou, J., Xu, H., Fan, D., Ran, L., Li, J., Wu, S., et al. (2020). MiR319a-targeted PtoTCP20 regulates secondary growth via interactions with PtoWOX4 and PtoWND6 in Populus tomentosa. New Phytol. 228, 1354-1368. doi: 10.1111/ nph.16782

Ibañes, M., Fàbregas, N., Chory, J., and Caño-Delgado, A. I. (2009). Brassinosteroid signaling and auxin transport are required to establish the periodic pattern of Arabidopsis shoot vascular bundles. Proc. Natl. Acad. Sci. U. S. A. 106, 13630-13635. doi: 10.1073/pnas.0906416106

Immanen, J., Nieminen, K., Smolander, O. P., Kojima, M., Alonso Serra, J., Koskinen, P., et al. (2016). Cytokinin and auxin display distinct but interconnected distribution and signaling profiles to stimulate cambial activity. Curr. Biol. 26, 1990-1997. doi: 10.1016/j.cub.2016.05.053

Inoue, T., Higuchi, M., Hashimoto, Y., Seki, M., Kobayashi, M., Kato, T., et al. (2001). Identification of CRE1 as a cytokinin receptor from Arabidopsis. Nature 409, 1060-1063. doi: 10.1038/35059117

Ji, J., Strable, J., Shimizu, R., Koenig, D., Sinha, N., and Scanlon, M. J. (2010). WOX4 promotes procambial development. Plant Physiol. 152, 1346-1356. doi: $10.1104 /$ pp.109.149641

Kondo, Y., Ito, T., Nakagami, H., Hirakawa, Y., Saito, M., Tamaki, T., et al. (2014). Plant GSK3 proteins regulate xylem cell differentiation downstream of TDIF-TDR signalling. Nat. Commun. 5:3504. doi: 10.1038/ncomms4504

Kubo, M., Udagawa, M., Nishikubo, N., Horiguchi, G., Yamaguchi, M., Ito, J., et al. (2005). Transcription switches for protoxylem and metaxylem vessel formation. Genes Dev. 19, 1855-1860. doi: 10.1101/gad.1331305

Kucukoglu, M., Nilsson, J., Zheng, B., Chaabouni, S., and Nilsson, O. (2017). WUSCHEL-RELATED HOMEOBOX4 (WOX4)-like genes regulate cambial cell division activity and secondary growth in Populus trees. New Phytol. 215, 642-657. doi: 10.1111/nph.14631

Lee, J., Kim, H., Park, S. G., Hwang, H., Yoo, S. I., Bae, W., et al. (2021). Brassinosteroid-BZR1/2-WAT1 module determines the high level of auxin signalling in vascular cambium during wood formation. New Phytol. 230, 1503-1516. doi: 10.1111/nph.17265 
Love, J., Björklund, S., Vahala, J., Hertzberg, M., Kangasjärvi, J., and Sundberg, B. (2009). Ethylene is an endogenous stimulator of cell division in the cambial meristem of Populus. Proc. Natl. Acad. Sci. U. S. A. 106, 5984-5989. doi: 10.1073/pnas.0811660106

Mähönen, A. P., Higuchi, M., Törmäkangas, K., Miyawaki, K., Pischke, M. S., Sussman, M. R., et al. (2006). Cytokinins regulate a bidirectional phosphorelay network in Arabidopsis. Curr. Biol. 16, 1116-1122. doi: 10.1016/j. cub.2006.04.030

Matsumoto-Kitano, M., Kusumoto, T., Tarkowski, P., Kinoshita-Tsujimura, K., Vaclavikova, K., Miyawaki, K., et al. (2008). Cytokinin kinins are central regulators of cambial activity. Proc. Natl. Acad. Sci. U. S. A. 105, 20027-20031. doi: $10.1073 /$ pnas. 0805619105

Mauriat, M., and Moritz, T. (2009). Analyses of GA20ox- and GID1-overexpressing aspen suggest that gibberellins play two distinct roles in wood formation. Plant J. 58, 989-1003. doi: 10.1111/j.1365-313X.2009.03836.x

Mauseth, J. D. (2016). Botany: An Introduction to Plant Biology. Burlington: Jones \& Bartlett Learning.

Mayer, K. F. X., Schoof, H., Haecker, A., Lenhard, M., Jurgens, G., and Laux, T. (1998). Role of WUSCHEL in regulating stem cell fate in the Arabidopsis shoot meristem. Cell 95, 805-815. doi: 10.1016/ S0092-8674(00)81703-1

McConnell, J. R., Emery, J., Eshed, Y., Bao, N., Bowman, J., and Barton, M. K. (2001). Role of PHABULOSA and PHAVOLUTA in determining radial patterning in shoots. Nature 411, 709-713. doi: 10.1038/35079635

Mitsuda, N., Iwase, A., Yamamoto, H., Yoshida, M., Seki, M., Shinozaki, K., et al. (2007). NAC transcription factors, NST1 and NST3, are key regulators of the formation of secondary walls in woody tissues of Arabidopsis. Plant Cell 19, 270-280. doi: 10.1105/tpc.106.047043

Miyashima, S., Sebastian, J., Lee, J. Y., and Helariutta, Y. (2013). Stem cell function during plant vascular development. $E M B O$ J. 32, 178-193. doi: 10.1038/emboj.2012.301

Mizrachi, E., and Myburg, A. A. (2016). Systems genetics of wood formation. Curr. Opin. Plant Biol. 30, 94-100. doi: 10.1016/j.pbi.2016.02.007

Nieminen, K., Blomster, T., Helariutta, Y., and Mähönen, A. P. (2015). Vascular cambium development. Arabidopsis Book 13:e0177. doi: 10.1199/ tab.0177

Nieminen, K., Immanen, J., Laxell, M., Kauppinen, L., Tarkowski, P., Dolezal, K., et al. (2008). Cytokinin signaling regulates cambial development in poplar. Proc. Natl. Acad. Sci. U. S. A. 105, 20032-20037. doi: 10.1073/ pnas. 0805617106

Nilsson, J., Karlberg, A., Antti, H., Lopez-Vernaza, M., Mellerowicz, E., Perrot-Rechenmann, C., et al. (2008). Dissecting the molecular basis of the regulation of wood formation by auxin in hybrid aspen. Plant Cell 20, 843-855. doi: 10.1105/tpc.107.055798

Ohashi-Ito, K., Saegusa, M., Iwamoto, K., Oda, Y., Katayama, H., Kojima, M., et al. (2014). A bHLH complex activates vascular cell division via cytokinin action in root apical meristem. Curr. Biol. 24, 2053-2058. doi: 10.1016/j. cub.2014.07.050

Ortega-Martinez, O., Pernas, M., Carol, R. J., and Dolan, L. (2007). Ethylene modulates stem cell division in the Arabidopsis thaliana root. Science 317, 507-510. doi: 10.1126/science.1143409

Ramachandran, P., Carlsbecker, A., and Etchells, J. P. (2017). Class III HD-ZIPs govern vascular cell fate: an $\mathrm{HD}$ view on patterning and differentiation. J. Exp. Bot. 68, 55-69. doi: 10.1093/jxb/erw370

Robischon, M., Du, J., Miura, E., and Groover, A. (2011). The Populus class III HD ZIP, popREVOLUTA, influences cambium initiation and patterning of woody stems. Plant Physiol. 155, 1214-1225. doi: 10.1104/pp.110.167007

Sarkar, A. K., Luijten, M., Miyashima, S., Lenhard, M., Hashimoto, T., Nakajima, K., et al. (2007). Conserved factors regulate signalling in Arabidopsis thaliana shoot and root stem cell organizers. Nature 446, 811-814. doi: 10.1038/ nature 05703

Schoof, H., Lenhard, M., Haecker, A., Mayer, K. F., Jurgens, G., and Laux, T. (2000). The stem cell population of Arabidopsis shoot meristems in maintained by a regulatory loop between the CLAVATA and WUSCHEL genes. Cell 10, 635-644. doi: 10.1016/s0092-8674(00)80700-x

Shi, D., Lebovka, I., López-Salmerón, V., Sanchez, P., and Greb, T. (2019). Bifacial cambium stem cells generate xylem and phloem during radial plant growth. Development 146:dev171355. doi: 10.1242/dev.171355
Smet, W., Sevilem, I., de Luis Balaguer, M. A., Wybouw, B., Mor, E., Miyashima, S., et al. (2019). DOF2.1 controls cytokinin-dependent vascular cell proliferation downstream of TMO5/LHW. Curr. Biol. 29, 520.e6-529.e6. doi: 10.1016/j. cub.2018.12.041

Smetana, O., Mäkilä, R., Lyu, M., Amiryousefi, A., Rodríguez, F. S., Wu, M. F., et al. (2019). High levels of auxin signalling define the stem-cell organizer of the vascular cambium. Nature 565, 485-489. doi: 10.1038/s41586-018-0837-0

Smit, M. E., McGregor, S. R., Sun, H., Gough, C., Bågman, A., Soyars, C. L., et al. (2020). A PXY-mediated transcriptional network integrates signaling mechanisms to control vascular development in Arabidopsis. Plant Cell 32, 319-335. doi: 10.1105/tpc. 19.00562

Suer, S., Agusti, J., Sanchez, P., Schwarz, M., and Greb, T. (2011). WOX4 imparts auxin responsiveness to cambium cells in Arabidopsis. Plant Cell 23, 3247-3259. doi: 10.1105/tpc.111.087874

Takata, N., Awano, T., Nakata, M. T., Sano, Y., Sakamoto, S., Mitsuda, N., et al. (2019). Populus NST/SND orthologs are key regulators of secondary cell wall formation in wood fibers, phloem fibers and xylem ray parenchyma cells. Tree Physiol. 39, 514-525. doi: 10.1093/treephys/tpz004

Tang, X., Wang, D., Liu, Y., Lu, M., Zhuang, Y., Xie, Z., et al. (2020). Dual regulation of xylem formation by an auxin-mediated PaC3H17-PaMY B199 module in Populus. New Phytol. 225, 1545-1561. doi: 10.1111/ nph.16244

Tuskan, G. A., Difazio, S., Jansson, S., Bohlmann, J., Grigoriev, I., Hellsten, U., et al. (2006). The genome of black cottonwood, Populus trichocarpa (Torr. \& Gray). Science 313, 1596-1604. doi: 10.1126/science.1128691

Wang, L., Cui, J., Jin, B., Zhao, J., Xu, H., Lu, Z., et al. (2020). Multifeature analyses of vascular cambial cells reveal longevity mechanisms in old Ginkgo biloba trees. Proc. Natl. Acad. Sci. U. S. A. 117, 2201-2210. doi: 10.1073/ pnas. 1916548117

Weijers, D., and Wagner, D. (2016). Transcriptional responses to the auxin hormone. Аnnu. Rev. Plant Biol. 67, 539-574. doi: 10.1146/annurevarplant-043015-112122

Wenzel, C. L., Schuetz, M., Yu, Q., and Mattsson, J. (2007). Dynamics of MONOPTEROS and PIN-FORMED1 expression during leaf vein pattern formation in Arabidopsis thaliana. Plant J. 49, 387-398. doi: 10.1111/j.1365-313X.2006.02977.x

Xu, C., Shen, Y., He, F., Fu, X., Yu, H., Lu, W., et al. (2019). Auxin-mediated Aux/IAA-ARF-HB signaling cascade regulates secondary xylem development in Populus. New Phytol. 222, 752-767. doi: 10.1111/nph.15658

Yang, J. H., Lee, K. H., Du, Q., Yang, S., Yuan, B., Qi, L., et al. (2020a). A membrane-associated NAC domain transcription factor XVP interacts with TDIF co-receptor and regulates vascular meristem activity. New Phytol. 226, 59-74. doi: 10.1111/nph.16289

Yang, S., Wang, S., Li, S., Du, Q., Qi, L., Wang, W., et al. (2020b). Activation of ACS7 in Arabidopsis affects vascular development and demonstrates a link between ethylene synthesis and cambial activity. J. Exp. Bot. 71, 7160-7170. doi: $10.1093 /$ jxb/eraa423

Zhang, J., Eswaran, G., Alonso-Serra, J., Kucukoglu, M., Xiang, J., Yang, W., et al. (2019). Transcriptional regulatory framework for vascular cambium development in Arabidopsis roots. Nat. Plants 5, 1033-1042. doi: 10.1038/ s41477-019-0522-9

Zhao, Y., Song, X., Zhou, H., Wei, K., Jiang, C., Wang, J., et al. (2020). KNAT2/6b, a class I KNOX gene, impedes xylem differentiation by regulating NAC domain transcription factors in poplar. New Phytol. 225, 1531-1544. doi: $10.1111 /$ nph. 16036

Zheng, S., He, J., Lin, Z., Zhu, Y., Sun, J., and Li, L. (2021). Two MADS-box genes regulate vascular cambium activity and secondary growth by modulating auxin homeostasis in Populus. Plant Commun. 2:100134. doi: 10.1016/j. xplc.2020.100134

Zhong, R., Demura, T., and Ye, Z. (2006). SND1, a NAC domain transcription factor, is a key regulator of secondary wall synthesis in fibers of Arabidopsis. Plant Cell 18, 3158-3170. doi: 10.1105/tpc.106.047399

Zhou, J., Zhong, R., and Ye, Z. H. (2014). Arabidopsis NAC domain proteins, VND1 to VND5, are transcriptional regulators of secondary wall biosynthesis in vessels. PLoS One 9:e105726. doi: 10.1371/journal.pone.0105726

Zhu, Y., Song, D., Sun, J., Wang, X., and Li, L. (2013). PtrHB7, a class III HD-Zip gene, plays a critical role in regulation of vascular cambium differentiation in Populus. Mol. Plant 6, 1331-1343. doi: 10.1093/mp/sss164 
Zhu, Y., Song, D., Xu, P., Sun, J., and Li, L. (2018). A HD-ZIP III gene, PtrHB4, is required for interfascicular cambium development in Populus. Plant Biotechnol. J. 16, 808-817. doi: 10.1111/pbi.12830

Conflict of Interest: The authors declare that the research was conducted in the absence of any commercial or financial relationships that could be construed as a potential conflict of interest.

Publisher's Note: All claims expressed in this article are solely those of the authors and do not necessarily represent those of their affiliated organizations, or those of the publisher, the editors and the reviewers. Any product that may be evaluated in this article, or claim that may be made by its manufacturer, is not guaranteed or endorsed by the publisher.

Copyright $\odot 2021$ Wang, Chen, Li, Li, Lu, Zhou and Chai. This is an open-access article distributed under the terms of the Creative Commons Attribution License (CC BY). The use, distribution or reproduction in other forums is permitted, provided the original author(s) and the copyright owner(s) are credited and that the original publication in this journal is cited, in accordance with accepted academic practice. No use, distribution or reproduction is permitted which does not comply with these terms. 